\title{
Polymorphisms in folate pathway and pemetrexed treatment outcome in patients with malignant pleural mesothelioma
}

\author{
Katja Goricar ${ }^{1}$, Viljem Kovac², Vita Dolzan ${ }^{1}$ \\ ${ }^{1}$ Pharmacogenetics Laboratory, Institute of Biochemistry, Faculty of Medicine, University of Ljubljana, Ljubljana, Slovenia \\ ${ }^{2}$ Institute of Oncology Ljubljana, Ljubljana, Slovenia \\ Radiol Oncol 2014; 48(2): 163-172. \\ Received 12 October 2013 \\ Accepted 23 October 2013
}

Correspondence to: Prof. Vita Dolžan, Ph.D., M.D., Pharmacogenetics Laboratory, Institute of Biochemistry, Faculty of Medicine, University of Ljubljana, Vrazov trg 2, 1000 Ljubljana, Slovenia. Phone: +386 1543 7670; Fax: +386 1543 7641; E-mail: vita.dolzan@mf.uni-lj.si

Disclosure: No potential conflicts of interest are disclosed.

Introduction. A combination of pemetrexed and cisplatin has been shown to improve the outcome in patients with malignant pleural mesothelioma (MPM), however, there is a great heterogeneity in treatment response among patients. The aim of our study was to evaluate the influence of polymorphisms in folate pathway and transporter genes on pemetrexed treatment outcome in Slovenian patients with MPM.

Methods. MPM patients treated with pemetrexed in the course of a prospective randomized clinical trial were genotyped for nineteen polymorphisms in five genes of folate pathway and six transporter genes. Logistic regression was used to assess the influence of polymorphisms on treatment efficacy and toxicity, while Cox regression was used to determine their influence on progression-free and overall survival.

Results. Patients with at least one polymorphic MTHFD 1 rs2236225 allele had a significantly lower response rate $(p=$ 0.005 ; odds ratio $[\mathrm{OR}]=0.12 ; 95 \%$ confidence interval $[\mathrm{Cl}]=0.03-0.54)$ and shorter progression-free survival $(p=0.032$; hazard ratio $[H R]=3.10 ; 95 \% \mathrm{Cl}=1.10-8.74)$ than non-carriers. Polymorphisms in transporter genes did not influence survival; however, several were associated with toxicity. Liver toxicity was significantly lower in carriers of polymorphic $A B C C 2$ rs2273697 ( $p=0.028 ; O R=0.23 ; 95 \% \mathrm{Cl}=0.06-0.85)$, SLCO1B1 rs4149056 ( $p=0.028 ; \mathrm{OR}=0.23 ; 95 \% \mathrm{Cl}=$ $0.06-0.85$ ) and $r s 1045879$ ( $p=0.014 ; O R=0.18 ; 95 \% \mathrm{Cl}=0.05-0.71$ ) alleles compared to non-carriers, as well as in patients with SLCOIBI GCAC haplotype ( $p=0.048$; OR $=0.17 ; 95 \% \mathrm{Cl}=0.03-0.98)$. Gastrointestinal toxicity was much more common in patients with polymorphic $A B C C 2$ rs717620 allele $(p=0.004 ; O R=10.67 ; 95 \% \mathrm{Cl}=2.15-52.85)$ and ABCC2 CAG haplotype ( $p=0.006$; OR $=5.67 ; 95 \% \mathrm{Cl}=1.64-19.66)$.

Conclusions. MTHFDI polymorphism affected treatment response and survival, while polymorphisms in $A B C C 2$ and SLCOIBI transporter genes influenced the risk for toxicity. These polymorphisms could serve as potential markers of pemetrexed treatment outcome in patients with MPM.

Key words: mesothelioma; pemetrexed; polymorphism; folate pathway; toxicity

\section{Introduction}

Malignant pleural mesothelioma (MPM) is a rare but aggressive tumour of mesothelial surfaces of pleura that is mainly connected with asbestos exposure. ${ }^{1}$ Most patients are diagnosed in later stages, often with unresectable disease, therefore the prognosis is poor and median survival time is rarely above two years. ${ }^{2,3}$ Several clinical and genetic factors can have a prognostic value in MPM, but successful treatment remains challenging. ${ }^{2}$ Most patients with MPM are treated with systemic chemotherapy; usually either pemetrexed (PMX) or gemcitabine combined with a platinum agent, which are often used in different oncological diseases.. ${ }^{4-6}$ Studies have shown that chemotherapy significantly improves survival of patients with MPM. Randomized clinical trial has shown that treatment with combination of PMX and cisplatin improves outcome in patients with $\mathrm{MPM}^{7-9}$ and 
TABLE 1. Clinical and treatment characteristics of patients with malignant pleural mesothelioma receiving pemetrexed (PMX) chemotherapy

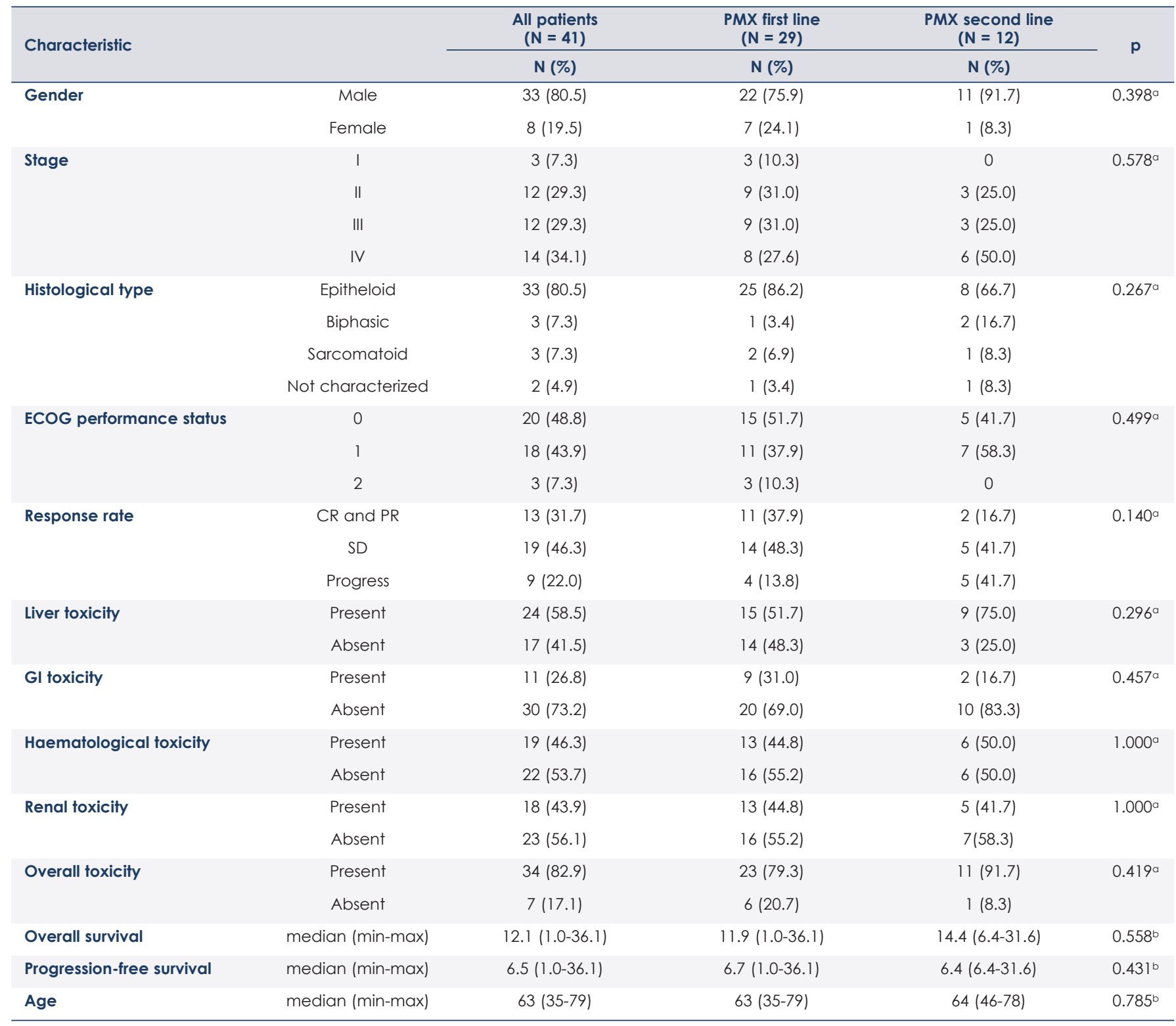

${ }^{a}$ Calculated using Fisher's exact test; ${ }^{b}$ Calculated using Mann-Whitney U-test; $C R=$ complete response; PR = partial response; $S D=$ stable disease; ECOG = Eastern Cooperative Oncology Group; $\mathrm{Gl}=$ gastrointestinal

comparable results were obtained for treatment with gemcitabine and cisplatin. $3,4,10$

PMX is a folic acid analogue, frequently used in treatment of MPM or non-small cell lung cancer (NSCLC). It inhibits several key folate pathway enzymes, including thymidylate synthase (TYMS), thus leading to impaired DNA synthesis. ${ }^{11}$ Several other enzymes such as MTHFD1, MTHFR, MTR, and MTRR, participate in folate metabolic pathway and may influence treatment with antifolates. ${ }^{12}$

The efficacy of PMX may also depend on its transport into and out of the cell. The most im- portant for PMX uptake is reduced folate carrier (SLC19A1), but hepatic SLCO1B1 transporter is also involved in antifolate transport. ${ }^{13}$ On the other hand, ATP-binding cassette $(\mathrm{ABC})$ transporters are involved in efflux of PMX from the cells. ${ }^{14,15}$

Response rate to PMX treatment is up to $40 \%$ in patients with $\mathrm{MPM}^{3}$ and toxicity of PMX may be dose limiting. Differences in response to treatment with PMX may be partly due to genetic variability of enzymes involved in its transport and metabolism. Single nucleotide polymorphisms (SNPs) in folate pathway and folate transporter genes have 
been extensively studied regarding their impact on toxicity and efficacy of methotrexate, the most common antifolate used in chemotherapy. Regarding PMX, a newer antifolate agent, only a few studies of TYMS, MTHFR, and SLC19A1 polymorphisms in NSCLC were published to date. ${ }^{16,17}$ Very little is known about the influence of these polymorphisms on response to treatment with PMX in MPM. ${ }^{18}$

The aim of this study was therefore to evaluate how polymorphisms in folate pathway genes (TYMS, MTHFR, MTHFD1, MTR, MTRR) and transporter genes (SLC19A1, SLCO1B1, ABCB1, $A B C C 2, A B C G 2)$ affect treatment outcome, toxicity and survival in Slovenian patients with MPM, treated with PMX.

\section{Patients and methods}

\section{Patients}

Patients eligible for inclusion in the pharmacogenetic study had histologically proven MPM and were participating in an ongoing prospective randomised phase II clinical trial "Cisplatin with either Alimta or Gemcitabine in long infusion (AGILI) for mesothelioma" (Trial registration ID: NCT01281800) at the Institute of Oncology Ljubljana, Slovenia. ${ }^{19}$ Patients that meet the trial's inclusion criteria were randomized in two groups, receiving either PMX or gemcitabine in combination with cisplatin. ${ }^{19}$ Patients in which cisplatin was substituted with carboplatin due to poor performance status or renal dysfunction were also included. If disease progression occurred, chemotherapy regimen was switched in second line.

Patients were diagnosed mostly at the University Clinic of Pulmonary and Allergic Diseases in Golnik, Slovenia and treated at the Institute of Oncology Ljubljana, Slovenia. Clinical data were obtained from the medical records or assessed during the clinical interview.

The study was approved by the Slovenian Ethics Committee for Research in Medicine and was carried out according to the Declaration of Helsinki.

\section{Response, survival and toxicity assessment}

Tumour response was evaluated using modified Response Evaluation Criteria in Solid Tumours (RECIST) ${ }^{20}$ Response rate was defined as the percentage of patients achieving partial or complete response. Progression-free survival (PFS) and overall survival (OS) were evaluated in survival analysis.
Haematological toxicity (anaemia, leucopoenia, neutropenia, and thrombocytopenia), liver toxicity, renal toxicity, and gastrointestinal (GI) toxicity were evaluated according to National Cancer Institute Common Terminology Criteria for Adverse Events, version 4.0.21

\section{DNA extraction and genotyping}

Peripheral blood samples were collected before the first day of the treatment. Extraction of genomic DNA from frozen whole-blood samples was performed according to the manufacturer's instructions using Qiagen FlexiGene kit (Qiagen, Hilden, Germany).

We genotyped 19 different polymorphisms in five folate pathway and six transporter genes. MTHFD1 rs2236225 (Arg653Gln), MTHFR rs1801133 (Ala222Val) and rs1801131 (Glu429Ala), SLCO1B1 rs2306283 (Asn130Asp), and ABCB1 rs1045642 (Ile1145Ile) polymorphisms were determined using TaqMan SNP Genotyping assays according to the manufacturer's instructions (Applied Biosystems, Foster City, CA) as previously described. ${ }^{22}$ Genotyping of MTRR rs1801394 (Ile22Met), MTR rs1805087 (Asp919Gly), SLC19A1 rs1051266 (Arg27Cys), SLCO1B1 rs11045879 (intronic), rs4149056 (Val174Ala) and rs2900478 (intronic), $A B C C 2$ rs717620 (5' untranslated region (UTR) -24C>T), rs2273697 (Val417lle) and rs2804402 (5' UTR -1019A>G), ABCC4 rs2274407 (Lys304Asn), and ABCG2 rs2231142 (Gln141Lys) and rs2231137 (Val12Met) polymorphisms was carried out using a fluorescence-based competitive allele-specific (KASPar) assay according to the manufacturer's instructions (KBiosciences, Herts, UK). Determination of promoter TYMS rs34743033 (5' UTR 2R $>3 \mathrm{R}$ ) polymorphism ${ }^{23}$ and $A B C B 1$ rs2032582 (Ala893Ser/Thr) polymorphism was carried out using PCR amplification followed by the analysis of PCR fragments on agarose gel as previously described. ${ }^{24}$

\section{Statistical analyses}

Median and range (minimum-maximum) were used to present central tendency and variability. To assess deviation from Hardy-Weinberg equilibrium (HWE), standard chi-square test was used. A dominant genetic model was used in all statistical analyses. The influences of genetic polymorphisms on treatment outcome were examined by univariable logistic regression to calculate odds ratios (ORs) and their 95\% confidence intervals (CIs). In 
TABLE 2. The influence of investigated polymorphisms on response rate, overall survival $(\mathrm{N}=41)$ and progression-free survival $(\mathrm{N}=29)$ in patients with malignant pleural mesothelioma

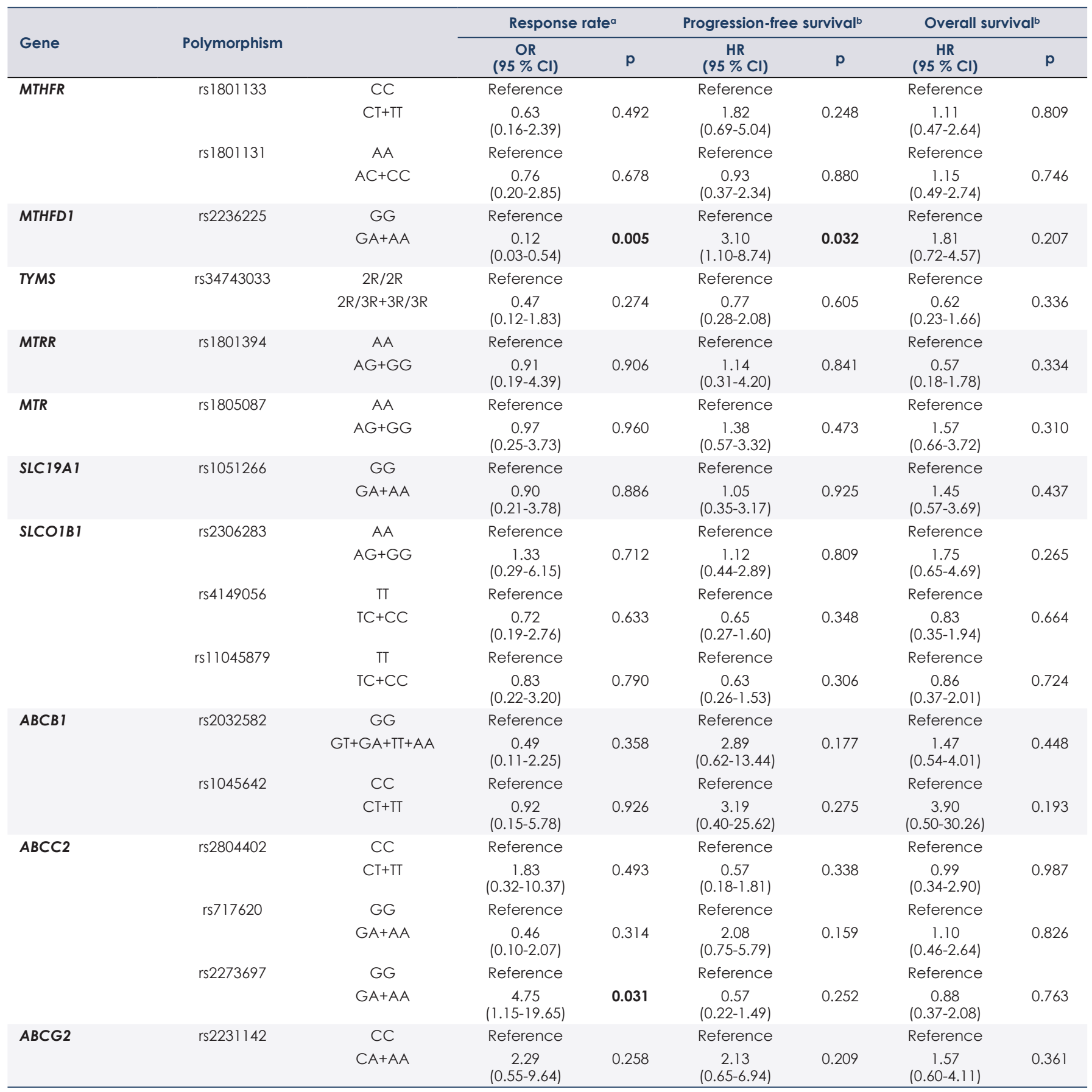

acalculated using logistic regression; ${ }^{b}$ calculated by Cox proportional hazards model and adjusted for C-reactive protein level

survival analysis Cox proportional hazards model was used and the hazard ratio (HR) with the $95 \%$ $\mathrm{CI}$ was determined. All potential clinical and treatment predictors were also independently analysed for their influence on treatment outcome. All statis- tical analyses were carried out by Statistical Package for the Social Sciences (SPSS) for Windows, version 19.0 (IBM Corporation, Armonk, NY, USA).

Haplotypes were reconstructed and analysed using Thesias software ${ }^{25}$ as described previously. ${ }^{26}$ 
Only haplotypes with frequencies above $5 \%$ were included in the statistical analyses and the most frequent haplotype was used as reference.

All statistical tests were two-sided and the level of significance was set to 0.05 . Due to the exploratory nature of the study, no adjustments for multiple comparisons were used.

\section{Results}

\section{Patients' characteristics}

In our study, we included 41 patients with MPM, participating in the AGILI trial from 2008 to December 2012. In total, 29 patients received PMX as first line of chemotherapy and 12 received PMX as second line. Clinical characteristics of the study group are summarized in Table 1 . Twenty (48.8\%) patients were smokers and $33(80.5 \%)$ were either occupationally or environmentally exposed to asbestos. Median C-reactive protein (CRP) level at diagnosis was $23 \mathrm{mg} / \mathrm{l}$ (range: 1-192 mg/l). The majority of patients $(70.7 \%)$ received at least $4 \mathrm{cy}-$ cles of chemotherapy. To the date of the analysis, disease progression occurred in $32(78.0 \%)$ patients and 23 patients $(56.1 \%)$ had died. There were no significant differences between patients receiving PMX as the first or second line of chemotherapy (Table 1).

\section{Genotyping analysis}

All genotype frequencies (Supplemental Table 1) were in agreement with $\operatorname{HWE}(p>0.05)$. Three SNPs were excluded from further statistical analyses: SLCO1B1 rs2900478 was in complete linkage disequilibrium (LD) with SLCO1B1 rs11045879, while ABCG2 rs2231137 and ABCC4 rs2274407 were too rare.

\section{Tumour response analysis}

Among 41 patients, one $(2.4 \%)$ was a complete responder and 12 (29.3\%) were partial responders, meaning the overall response rate was $31.7 \%$. Nineteen patients had stable disease and nine had progressive disease. Data on the influence of polymorphisms on response rate are presented in Table 2. Patients with at least one polymorphic MTHFD1 rs2236225 allele had lower response rate $(p=0.005 ; \mathrm{OR}=0.12 ; 95 \% \mathrm{CI}=0.03-0.54)$ than patients with two wild-type alleles. On the other hand, patients with at least one polymorphic ABCC2 rs2273697 had significantly better response rate than non-carriers $(p=0.031 ; \mathrm{OR}=4.75 ; 95 \% \mathrm{CI}$ =1.15-19.65).

Higher TNM stage was the only clinical parameter significantly associated with lower response rate $(p=0.013 ; \mathrm{OR}=0.35 ; 95 \% \mathrm{CI}=0.15-0.79)$. After adjustment for TNM stage, MTHFD1 rs2236225 remained associated with response rate $(p=0.016$; OR $=0.14 ; 95 \% \mathrm{CI}=0.03-0.70)$, but the effect of $A B C C 2$ rs2273697 was no longer significant $(p=0.065 ; \mathrm{OR}=$ $4.32 ; 95 \% \mathrm{CI}=0.91-20.43)$.

\section{Toxicity analysis}

Several polymorphisms in transporter genes influenced occurrence of treatment-related toxicities. ABCC2 rs2273697 conferred protection against development of any toxicity $(p=0.035 ; \mathrm{OR}=0.09$; $95 \% \mathrm{CI}=0.01-0.85)$. Liver toxicity was significantly less frequent in carriers of polymorphic SLCO1B1 rs11045879 $(p=0.014 ; \mathrm{OR}=0.18 ; 95 \% \mathrm{CI}=0.05-0.71)$ and $\mathrm{rs} 4149056(p=0.028 ; \mathrm{OR}=0.23 ; 95 \% \mathrm{CI}=$ 0.06-0.85) alleles. ABCC2 rs2273697 was also associated with decreased liver toxicity $(p=0.028$; OR $=0.23 ; 95 \% \mathrm{CI}=0.06-0.85)$. On the other hand, GI toxicity was much more common in patients with polymorphic $A B C C 2$ rs717620 allele ( $p=0.004$; OR $=10.67 ; 95 \% \mathrm{CI}=2.15-52.85)$. The other investigated polymorphisms in transporter and folate pathway genes did not significantly affect occurrence of either overall or specific toxicity (Table 3 and Supplemental Table 2).

\section{Survival analysis}

Analysis of OS was performed in the whole cohort of patients, while PFS was only analysed in the group of patients receiving PMX in the first line treatment. Firstly, clinical and treatment characteristics were examined for their influence on PFS or OS. Increased level of CRP before the first day of the treatment was the only parameter associated both with shorter PFS and shorter OS $(p=0.002$, $\mathrm{HR}=1.015,95 \% \mathrm{CI}=1.01-1.03$ and $p<0.001, \mathrm{HR}$ $=1.015,95 \% \mathrm{CI}=1.01-1.02$, respectively). Patients with sarcomatoid or biphasic MPM had significantly shorter PFS ( $p=0.026, \mathrm{HR}=4.59,95 \% \mathrm{CI}=$ 1.20-17.52). On the other hand, if patients received more chemotherapy cycles, OS was longer ( $p=$ $0.024, \mathrm{HR}=0.36,95 \% \mathrm{CI}=0.15-0.88)$. However, only CRP remained significant in multivariable model.

The data on the influence of SNPs on survival is presented in Table 2. Among the investigated polymorphisms, only MTHFD1 rs2236225 signifi- 
TABLE 3. The influence of investigated polymorphisms on liver and gastrointestinal $(G \mid)$ toxicity $(N=41)$

\begin{tabular}{|c|c|c|c|c|c|c|c|c|}
\hline \multirow[b]{2}{*}{ Gene } & \multirow[b]{2}{*}{ Polymorphism } & & \multicolumn{3}{|c|}{ Liver toxicity $^{a}$} & \multicolumn{3}{|c|}{ GI toxicity ${ }^{a}$} \\
\hline & & & N (\%) & $\begin{array}{c}\text { OR } \\
(95 \% \mathrm{Cl})\end{array}$ & $p$ & N (\%) & $\begin{array}{c}\text { OR } \\
(95 \% \mathrm{Cl})\end{array}$ & $p$ \\
\hline \multirow[t]{3}{*}{ MTHFR } & rs 1801133 & $\mathrm{CC}$ & $10(45.5)$ & Reference & & $6(27.3)$ & Reference & \\
\hline & rs 1801131 & AA & $10(58.8)$ & Reference & & $5(29.4)$ & Reference & \\
\hline & & $A C+C C$ & 14 (58.3) & $\begin{array}{c}0.98 \\
(0.28-3.46)\end{array}$ & 0.975 & $6(25.0)$ & $\begin{array}{c}0.80 \\
(0.20-3.22)\end{array}$ & 0.754 \\
\hline MTHFD 1 & & $\mathrm{GA}+\mathrm{AA}$ & $17(65.4)$ & $\begin{array}{c}2.16 \\
(0.59-7.90)\end{array}$ & 0.245 & $6(23.1)$ & $\begin{array}{c}0.60 \\
(0.15-2.46)\end{array}$ & 0.477 \\
\hline \multirow[t]{2}{*}{ TYMS } & rs34743033 & $2 R / 2 R$ & $7(50.0)$ & Reference & & $2(14.3)$ & Reference & \\
\hline & & $2 R / 3 R+3 R / 3 R$ & $17(63.0)$ & $\begin{array}{c}1.7 \\
(0.46-6.28)\end{array}$ & 0.426 & 9 (33.3) & $\begin{array}{c}3.00 \\
(0.55-16.38)\end{array}$ & 0.205 \\
\hline MTR & & $A G+G G$ & $9(56.3)$ & $\begin{array}{c}0.86 \\
(0.24-3.06)\end{array}$ & 0.812 & $6(37.5)$ & $\begin{array}{c}2.40 \\
(0.59-9.82)\end{array}$ & 0.223 \\
\hline \multirow[t]{2}{*}{ SLC19A1 } & rs 1051266 & GG & $6(50.0)$ & Reference & & 4 (33.3) & Reference & \\
\hline & & $G A+A A$ & $18(62.1)$ & $\begin{array}{c}1.64 \\
(0.42-6.36)\end{array}$ & 0.477 & $7(24.1)$ & $\begin{array}{c}0.64 \\
(0.15-2.77)\end{array}$ & 0.547 \\
\hline \multirow[t]{4}{*}{ SLCOIBI } & rs2306283 & AA & $9(81.8)$ & Reference & & $3(27.3)$ & Reference & \\
\hline & & $A G+G G$ & 15 (50.0) & $\begin{array}{c}0.22 \\
(0.04-1.21)\end{array}$ & 0.081 & $8(26.7)$ & $\begin{array}{c}0.97 \\
(0.21-4.59)\end{array}$ & 0.696 \\
\hline & rs4149056 & TT & 17 (73.9) & Reference & & $4(17.4)$ & Reference & \\
\hline & & $\mathrm{TC}+\mathrm{CC}$ & 7 (38.9) & $\begin{array}{c}0.23 \\
(0.06-0.85)\end{array}$ & 0.028 & 7 (38.9) & $\begin{array}{c}3.02 \\
(0.72-12.70)\end{array}$ & 0.131 \\
\hline$A B C B 1$ & & $\mathrm{CT}+\mathrm{TT}$ & $20(57.1)$ & $\begin{array}{c}0.67 \\
(0.11-4.13)\end{array}$ & 0.663 & 11 (31.4) & l & $0.167^{t}$ \\
\hline \multirow[t]{6}{*}{$A B C C 2$} & rs2804402 & $\mathrm{CC}$ & $8(88.9)$ & Reference & & $3(33.3)$ & Reference & \\
\hline & & $\mathrm{CT}+\mathrm{TT}$ & $16(50.0)$ & $\begin{array}{c}0.13 \\
(0.01-1.12)\end{array}$ & 0.063 & $8(25.0)$ & $\begin{array}{c}0.67 \\
(0.14-3.30)\end{array}$ & 0.619 \\
\hline & rs717620 & GG & $15(55.6)$ & Reference & & $3(11.1)$ & Reference & \\
\hline & & $G A+A A$ & $9(64.3)$ & $\begin{array}{c}1.44 \\
(0.38-5.45)\end{array}$ & 0.591 & $8(57.1)$ & $\begin{array}{c}10.67 \\
(2.15-52.85)\end{array}$ & 0.004 \\
\hline & rs2273697 & GG & $17(73.9)$ & Reference & & $6(26.31)$ & Reference & \\
\hline & & $\mathrm{GA}+\mathrm{AA}$ & $7(38.9)$ & $\begin{array}{c}0.23 \\
(0.06-0.85)\end{array}$ & 0.028 & 5 (27.8) & $\begin{array}{c}1.09 \\
(0.27-4.37)\end{array}$ & 0.903 \\
\hline \multirow[t]{2}{*}{$A B C G 2$} & rs2231142 & $\mathrm{CC}$ & 17 (56.7) & Reference & & $10(33.3)$ & Reference & \\
\hline & & $C A+A A$ & $7(63.6)$ & $\begin{array}{c}1.34 \\
(0.32-5.56)\end{array}$ & 0.689 & $1(9.1)$ & $\begin{array}{c}0.20 \\
(0.02-1.79)\end{array}$ & 0.150 \\
\hline
\end{tabular}

${ }^{a}$ Calculated using logistic regression; bcalculated using Fisher's exact test as there were no patients in one group 
cantly influenced PFS ( $p=0.032 ; \mathrm{HR}=3.10 ; 95 \%$ $\mathrm{CI}=1.10-8.74)$ after adjustment for CRP level (Figure 1). MPM patients with at least one polymorphic MTHFD1 allele and high CRP level had shorter survival than patients with two wild-type alleles and lower CRP level.

\section{Haplotype analysis}

Haplotype analysis was performed to assess the combined effect of SNPs within one gene. Three SLCO1B1 haplotypes (ATT, GCC, and GTT) had frequencies above $5 \%$ and covered approximately $98 \%$ of variability within this gene (Table 4 ). Liver toxicity was less common in patients with GCC haplotype. This haplotype included all the polymorphic alleles, associated with decreased liver toxicity in single SNP analysis, compared with the reference ATT haplotype ( $p=0.048 ; \mathrm{OR}=0.17 ; 95 \%$ $\mathrm{CI}=0.03-0.98$ ).

Four $A B C C 2$ haplotypes (CGG, CAG, TGG and TGA) covered all the variability within this gene (Table 4). GI toxicity was significantly more common in patients with CAG haplotype ( $p=0.006$; $\mathrm{OR}=5.67 ; 95 \% \mathrm{CI}=1.64-19.66$ ) with polymorphic rs717620 allele, associated with increased GI toxicity in single SNP analysis.

\section{Discussion}

Patients with MPM participating in a prospective randomized clinical trial were investigated for the influence of folate pathway and transporter polymorphisms on PMX treatment response. Among folate pathway genes only MTHFD1 was associated with response rate and survival, while transporters mainly influenced PMX-related toxicity.

Only few pharmacogenetic studies on PMX treatment have been published so far. The only study in MPM focused on TYMS rs34743033, a tandem repeat of 28 base pairs in the $5^{\prime}$ UTR promoter region that changes TYMS mRNA and protein expression..$^{18}$ Consistent with our results, no association of this polymorphism with treatment outcome was observed, even though both mRNA and protein expression significantly affected survival. ${ }^{18,27,28}$ Similar results were obtained in NSCLC. 17,29-32

In our study, the carriers of the polymorphic MTHFD1 rs2236225 allele had a significantly shorter PFS and were less likely to achieve complete or partial response, even after adjustment for TNM stage. MTHFD1 is essential for the generation of methylene-THF required for thymidylate synthesis

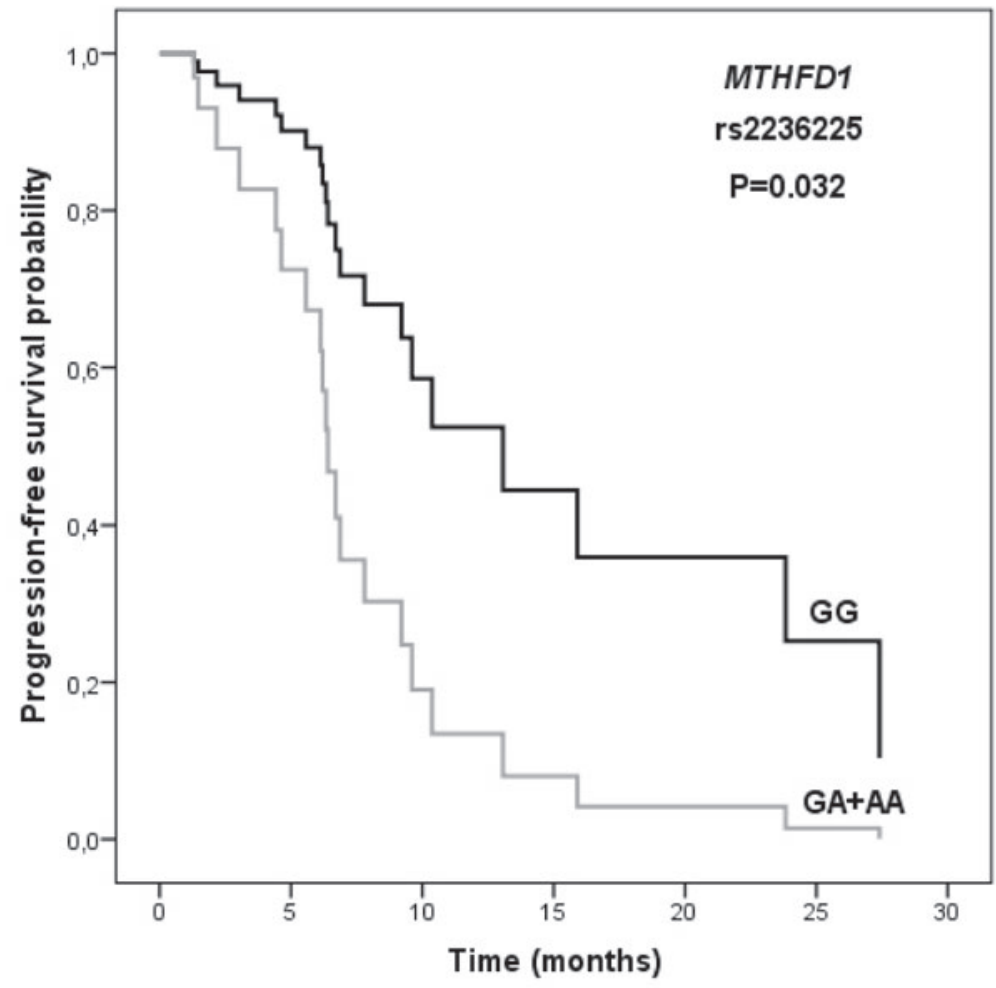

FIGURE 1. The influence of MTHFDI rs2236225 polymorphism on progression-free survival in patients with malignant pleural mesothelioma. P-value was calculated using Cox regression and adjusted for C-reactive protein level.

and MTHFD1 rs2236225 (Arg653Gln) was shown to reduce the enzyme activity ${ }^{33}$, leading to increased levels of methylene-THF and reducing cytotoxic effects of PMX. ${ }^{23,34}$ To our knowledge, no previous studies investigated the role of MTHFD1 SNPs in treatment with PMX. However, in some, but not all studies on methotrexate treatment in acute lymphoblastic leukaemia (ALL), the variant allele was associated with shorter event-free survival. ${ }^{23,34}$

In our MPM patients PMX treatment outcome was not influenced by other investigated folate pathway SNPs. Most of them have not been studied yet in PMX treated MPM patients, however in NSCLC polymorphic MTHFR rs1801133 allele conferred to increased survival in a recessive model. ${ }^{17,31}$

To our knowledge, this is the first study investigating folate transporter gene polymorphisms regarding treatment outcome in MPM. Patients with at least one polymorphic $A B C C 2$ rs2273697 allele had better response rate and less overall and liver toxicity than non-carriers, while polymorphic $A B C C 2$ rs717620 allele and $A B C C 2$ CAG haplotype conferred to increased GI toxicity. $A B C C 2$ encodes one of the multidrug resistance associated transporters, involved in transport of both natural folates and antifolate agents. ${ }^{35}$ The knowledge about the func- 
TABLE 4. The influence of SLCOIBI and $A B C C 2$ haplotypes on response rate, gastrointestinal $(\mathrm{Gl})$, and liver toxicity ( $N=41)$

\begin{tabular}{|c|c|c|c|c|c|c|c|c|}
\hline \multirow{2}{*}{ Gene } & \multirow{2}{*}{ Haplołype } & \multirow{2}{*}{$\begin{array}{l}\text { Estimated } \\
\text { frequency }\end{array}$} & \multicolumn{2}{|c|}{ Response rate } & \multicolumn{2}{|c|}{ GI toxicity } & \multicolumn{2}{|c|}{ Liver toxicity } \\
\hline & & & OR $(95 \% \mathrm{Cl})$ & $p$ & OR $(95 \% \mathrm{Cl})$ & $p$ & OR $(95 \% \mathrm{Cl})$ & $p$ \\
\hline \multirow[t]{2}{*}{ SLCOIB1 } & ATT & 0.47 & \multicolumn{2}{|c|}{ Reference } & \multicolumn{2}{|c|}{ Reference } & \multicolumn{2}{|c|}{ Reference } \\
\hline & GTT & 0.29 & $1.94(0.66-5.74)$ & 0.229 & $0.37(0.07-1.93)$ & 0.237 & $0.46(0.13-1.63)$ & 0.230 \\
\hline \multirow[t]{2}{*}{$A B C C 2$} & CGG & 0.28 & \multicolumn{2}{|c|}{ Reference } & \multicolumn{2}{|c|}{ Reference } & \multicolumn{2}{|c|}{ Reference } \\
\hline & TGA & 0.24 & $1.59(0.39-6.43)$ & 0.519 & $0.88(0.23-3.39)$ & 0.847 & $0.29(0.06-1.27)$ & 0.099 \\
\hline
\end{tabular}

tional significance of $A B C C 2$ SNPs is limited, but rs717620 was associated with decreased promoter activity and mRNA expression of $A B C C 2$, possibly affecting the accumulation of PMX in cells. 15,36 However, $A B C C 2$ is also involved in transport of platinum compounds and this could contribute to its effect on treatment response. Indeed, some studies have shown that rs717620 affects treatment with platinum agents in lung cancer..$^{37,38}$

In the present study, polymorphic SLCO1B1 rs11045879 and rs4149056 alleles were significantly associated with liver toxicity both in single SNP and haplotype analysis. SLCO1B1 encodes one of the main influx transporters expressed on the basolateral membrane of hepatocytes involved in uptake and clearance of many endogenous compounds and drugs, such as methotrexate. ${ }^{39}$ SLCO1B1 rs4149056 and rs2306283 were associated with decreased membrane expression and activity of the transporter..$^{39,40}$ Rs11045879 was identified in a genome-wide association study as the most important genetic factor associated with lower methotrexate clearance in patients with ALL. In later studies, a similar association with methotrexate clearance was observed for rs4149056. ${ }^{40,41}$

Although SLC19A1 is the predominant uptake transporter for antifolates, we observed no impact of rs1051266 on PMX treatment. Our results are consistent with studies on NSCLC ${ }^{17,31}$, although one study reported several other SLC19A1 SNPs associated with OS. ${ }^{16}$

Our study represents the first comprehensive pharmacogenetic study of treatment with PMX in MPM patients participating in a prospective randomized trial. As MPM is a rare cancer, some potential limitations of our study arise from its small sample size, such as low statistical power. However, the strength of our study was that all patients were from a homogenous population ${ }^{42}$, included in phase II clinical trial with well-defined inclusion criteria and clinical protocol, and treated in the same facility, thus minimizing the impact of other variables. We also evaluated the influence of potentially important clinical parameters and included haplotype analysis to evaluate the combined influence of more SNPs in one gene.

Both PMX and gemcitabine have shown comparable efficacy in MPM treatment. ${ }^{3,4}$ In previous studies, we have identified some polymorphisms that influence MPM treatment with gemcitabine and cisplatin. ${ }^{26,43,44}$ Our present results show for the first time that MTHFD1, ABCC2, and SLCO1B1 polymorphisms may play an important role in PMX treatment response in patients with MPM. These SNPs could serve as biomarkers for more personalized treatment and in the future, selection of treatment based on genetic factors may contribute to better treatment outcomes in patients with MPM.

\section{Supplementary files}

Supplemental Table 1. Distribution of genotype frequencies in patients with malignant pleural mesothelioma $(\mathrm{N}=41)$. Available from: http:// www.degruyter.com/view/j/raon.2014.48.issue-2/ raon-2013-0086/suppl/raon-2013-0086_supp1.pdf Supplemental Table 2 The influence of selected polymorphisms on overall toxicity, hematological and renal toxicity. Available from: http:// www.degruyter.com/view/j/raon.2014.48.issue-2/ raon-2013-0086/suppl/raon-2013-0086_supp2.pdf

\section{Acknowledgements}

The authors thank Barbara Možina, M.Sc., head of the Biochemistry Laboratory, Institute of Oncology 
Ljubljana, Slovenia, for her help with blood sample collections and handling. They also wish to acknowledge Nina Erčulj, Ph.D. for the initial help with data acquisition. The authors thank the staff from the University Clinic of Allergic and Pulmonary Disease Golnik, Slovenia for their help with diagnosis and treatment of malignant mesothelioma patients, particularly Izidor Kern, M.D. for performing the histopathological diagnosis and Prof. Tanja Čufer, M.D., Ph.D. and Nadja Triller, M.D. for providing first line treatment for one patient each. We wish to acknowledge Prof. Andrej Debeljak, M.D., Ph.D., Aleš Rozman, M.D., M.Sc., Matjaž Torel, M.D., M.Sc. and Prof. Anton Crnjac, M.D., Ph.D., for performing the invasive diagnostic procedures. We are also grateful to the team for lung cancer treatment at the Institute of Oncology Ljubljana, Slovenia for their help with patient treatment.

This work was financially supported by The Slovenian Research Agency (Grants L3-3648 and P1-0170).

\section{References}

1. Podobnik J, Kocijancic I, Kovac V, Sersa I. 3T MRI in evaluation of asbestosrelated thoracic diseases - preliminary results. Radiol Oncol 2010; 44: 92-6.

2. Mineo TC, Ambrogi V. Malignant pleural mesothelioma: factors influencing the prognosis. Oncology (Williston Park) 2012; 26: 1164-75.

3. Kovac V, Zwitter M, Zagar T. Improved survival after introduction of chemotherapy for malignant pleural mesothelioma in Slovenia: Population-based survey of 444 patients. Radiol Oncol 2012; 46: 136-44.

4. Lee CW, Murray N, Anderson H, Rao SC, Bishop W. Outcomes with firstline platinum-based combination chemotherapy for malignant pleural mesothelioma: a review of practice in British Columbia. Lung Cancer 2009; 64: 308-13.

5. Raeisi E, Aghamiri SMR, Bandi A, Rahmatpour N, Firoozabadi SM, Kafi-Abad SA, Mir LM. The antitumor efficiency of combined electrochemotherapy and single dose irradiation on a breast cancer tumor model. Radiol Oncol 2012; 46: 226-32.

6. Jeromen A, Oblak I, Anderluh F, Velenik V, Vidmar MS, Ratoša I. Results of postoperative radiochemotherapy of the patients with resectable gastroesophageal junction adenocarcinoma in Slovenia. Radiol Oncol 2012; 46: 337-45.

7. Vogelzang NJ, Rusthoven JJ, Symanowski J, Denham C, Kaukel E, Ruffie P, et al. Phase III study of pemetrexed in combination with cisplatin versus cisplatin alone in patients with malignant pleural mesothelioma. J Clin Oncol 2003; 21: 2636-44.

8. Berk S, Dogan OT, Kilickap S, Epozturk K, Akkurt I, Seyfikli Z. Clinical characteristics, treatment and survival outcomes in malignant mesothelioma: eighteen years' experience in Turkey. Asian Pac J Cancer Prev 2012; 13: 5735-9.

9. Helland A, Solberg S, Brustugun OT. Incidence and survival of malignant pleural mesothelioma in norway: a population-based study of 1686 cases. J Thorac Oncol 2012; 7: 1858-61.

10. Kovac V, Zwitter M, Rajer M, Marin A, Debeljak A, Smrdel U, et al. A phase II trial of low-dose gemcitabine in a prolonged infusion and cisplatin for malignant pleural mesothelioma. Anticancer Drugs 2012; 23: 230-8.

11. Kao SC, Phan VH, Clarke SJ. Predictive markers for haematological toxicity of pemetrexed. Curr Drug Targets 2010; 11: 48-57.
12. Berger SH, Pittman DL, Wyatt MD. Uracil in DNA: consequences for carcinogenesis and chemotherapy. Biochem Pharmacol 2008; 76: 697-706.

13. Franke RM, Sparreboom A. Drug transporters: recent advances and therapeutic applications. Clin Pharmacol Ther 2010; 87: 3-7.

14. Chattopadhyay S, Moran RG, Goldman ID. Pemetrexed: biochemical and cellular pharmacology, mechanisms, and clinical applications. Mol Cancer Ther 2007; 6: 404-17.

15. Silverton $L$, Dean $M$, Moitra K. Variation and evolution of the $A B C$ transporter genes $A B C B 1, A B C C 1, A B C G 2, A B C G 5$ and $A B C G 8$ : implication for pharmacogenetics and disease. Drug Metabol Drug Interact 2011; 26: 169-79.

16. Adjei AA, Salavaggione OE, Mandrekar SJ, Dy GK, Ziegler KL, Endo C, et al. Correlation between polymorphisms of the reduced folate carrier gene (SLC19A1) and survival after pemetrexed-based therapy in non-small cell lung cancer: a North Central Cancer Treatment Group-based exploratory study. J Thorac Oncol 2010; 5: 1346-53.

17. Tiseo M, Giovannetti E, Tibaldi C, Camerini A, Di Costanzo F, Barbieri F, et al. Pharmacogenetic study of patients with advanced non-small cell lung cancer (NSCLC) treated with second-line pemetrexed or pemetrexedcarboplatin. Lung Cancer 2012; 78: 92-9.

18. Zucali PA, Giovannetti E, Destro A, Mencoboni M, Ceresoli GL, Gianoncelli $L$, et al. Thymidylate synthase and excision repair cross-complementing group-1 as predictors of responsiveness in mesothelioma patients treated with pemetrexed/carboplatin. Clin Cancer Res 2011; 17: 2581-90.

19. Kovac V, Zwitter M. Cisplatin with Alimta or gemcitabine in long infusion for mesothelioma (AGILI). Available at: http://clinicaltrials.gov/ct2/show/ NCT01281800. Accessed January 16, 2013.

20. Byrne MJ, Nowak AK. Modified RECIST criteria for assessment of response in malignant pleural mesothelioma. Ann Oncol 2004; 15: 257-60.

21. National Cancer Institute Common Terminology Criteria for Adverse Events, version 4.0. Available at: http://ctep.cancer.gov/protocolDevelopment/ electronic_applications/ctc.htm. Accessed February 15, 2012

22. Erculj N, Kotnik BF, Debeljak M, Jazbec J, Dolzan V. The influence of folate pathway polymorphisms on high-dose methotrexate related toxicity and survival in children with non-Hodgkin malignant lymphoma. Radiol Oncol 2013; doi:10.2478/raon-2013-0076. 2013.10.26. [Epub ahead of print]

23. Erculj N, Kotnik BF, Debeljak M, Jazbec J, Dolzan V. Influence of folate pathway polymorphisms on high-dose methotrexate-related toxicity and survival in childhood acute lymphoblastic leukemia. Leuk Lymphoma 2012; 53: 1096-104.

24. Kastelic M, Koprivsek J, Plesnicar BK, Serretti A, Mandelli L, Locatelli I, et al. MDR1 gene polymorphisms and response to acute risperidone treatment. Prog Neuropsychopharmacol Biol Psychiatry 2010; 34: 387-92.

25. Tregouet DA, Garelle V. A new JAVA interface implementation of THESIAS: testing haplotype effects in association studies. Bioinformatics 2007; 23 : 1038-9.

26. Erculj N, Kovac V, Hmeljak J, Franko A, Dodic-Fikfak M, Dolzan V. The influence of gemcitabine pathway polymorphisms on treatment outcome in patients with malignant mesothelioma. Pharmacogenet Genomics 2012 22: 58-68.

27. Righi L, Papotti MG, Ceppi P, Bille A, Bacillo E, Molinaro L, et al. Thymidylate synthase but not excision repair cross-complementation group 1 tumor expression predicts outcome in patients with malignant pleural mesothelioma treated with pemetrexed-based chemotherapy. J Clin Oncol 2010; 28: $1534-9$.

28. Christoph DC, Asuncion BR, Mascaux C, Tran C, Lu X, Wynes MW, et al. Folylpoly-glutamate synthetase expression is associated with tumor response and outcome from pemetrexed-based chemotherapy in malignant pleural mesothelioma. J Thorac Oncol 2012; 7: 1440-8.

29. Christoph DC, Asuncion BR, Hassan B, Tran C, Maltzman JD, O'Shannessy $\mathrm{DJ}$, et al. Significance of folate receptor alpha and thymidylate synthase protein expression in patients with non-small-cell lung cancer treated with pemetrexed. J Thorac Oncol 2013; 8: 19-30.

30. Sun JM, Han J, Ahn JS, Park K, Ahn MJ. Significance of thymidylate synthase and thyroid transcription factor 1 expression in patients with nonsquamous non-small cell lung cancer treated with pemetrexed-based chemotherapy. $J$ Thorac Oncol 2011; 6: 1392-9. 
31. Smit EF, Burgers SA, Biesma B, Smit HJ, Eppinga P, Dingemans AM, et al. Randomized phase II and pharmacogenetic study of pemetrexed compared with pemetrexed plus carboplatin in pretreated patients with advanced non-small-cell lung cancer. J Clin Oncol 2009; 27: 2038-45.

32. Hu Q, Li X, Su C, Chen X, Gao G, Zhang J, et al. Correlation between thymidylate synthase gene polymorphisms and efficacy of pemetrexed in advanced non-small cell lung cancer. Exp Ther Med 2012; 4: 1010-6.

33. Christensen KE, Rohlicek CV, Andelfinger GU, Michaud J, Bigras JL, Richter A, et al. The MTHFD1 p.Arg653Gln variant alters enzyme function and increases risk for congenital heart defects. Hum Mutat 2009; 30: 212-20.

34. Krajinovic M, Lemieux-Blanchard E, Chiasson S, Primeau M, Costea I, Moghrabi A. Role of polymorphisms in MTHFR and MTHFD1 genes in the outcome of childhood acute lymphoblastic leukemia. Pharmacogenomics J 2004; 4: 66-72.

35. Ranganathan $P$, Culverhouse $R$, Marsh $S$, Mody A Scott-Horton $T$, Brasington R, et al. Methotrexate (MTX) pathway gene polymorphisms and their effects on MTX toxicity in Caucasian and African American patients with rheumatoid arthritis. J Rheumatol 2008; 35: 572-9.

36. Sai K, Saito Y, Itoda M, Fukushima-Uesaka H, Nishimaki-Mogami T, Ozawa $S$, et al. Genetic variations and haplotypes of ABCC2 encoding MRP2 in a Japanese population. Drug Metab Pharmacokinet 2008; 23: 139-47.

37. Sun N, Sun X, Chen B, Cheng H, Feng J, Cheng L, et al. MRP2 and GSTP1 polymorphisms and chemotherapy response in advanced non-small cell lung cancer. Cancer Chemother Pharmacol 2010; 65: 437-46.

38. Campa D, Muller P, Edler L, Knoefel L, Barale R, Heussel CP, et al. A comprehensive study of polymorphisms in $A B C B 1, A B C C 2$ and $A B C G 2$ and lung cancer chemotherapy response and prognosis. Int J Cancer 2012; 131: 2920-8.

39. Niemi M, Pasanen MK, Neuvonen PJ. Organic anion transporting polypeptide 1B1: a genetically polymorphic transporter of major importance for hepatic drug uptake. Pharmacol Rev 2011; 63: 157-81.

40. Trevino LR, Shimasaki N, Yang W, Panetta JC, Cheng C, Pei D, et al. Germline genetic variation in an organic anion transporter polypeptide associated with methotrexate pharmacokinetics and clinical effects. J Clin Oncol 2009; 27: 5972-8.

41. Ramsey LB, Bruun GH, Yang W, Trevino LR, Vattathil S, Scheet $P$, et al. Rare versus common variants in pharmacogenetics: SLCO1B1 variation and methotrexate disposition. Genome Res 2012; 22: 1-8.

42. Vidan-Jeras B, Jurca B, Dolzan V, Jeras M, Breskvar K, Bohinjec M. Slovenian Caucasian normal. In: Gjertson D, Terasaki P, editors. HLA 1998. Kansas: American society for histocompatibility and immunogenetics, Lenexa; 1998. p. $180-1$

43. Erculj N, Kovac V, Hmeljak J, Dolzan V. The influence of platinum pathway polymorphisms on the outcome in patients with malignant mesothelioma. Ann Oncol 2012; 23: 961-7.

44. Erculj N, Kovac V, Hmeljak J, Franko A, Dodic-Fikfak M, Dolzan V. DNA repair polymorphisms and treatment outcomes of patients with malignant mesothelioma treated with gemcitabine-platinum combination chemotherapy. J Thorac Oncol 2012; 7: 1609-17. 